\title{
Exhumaciones y memoria histórica en España: una mirada interdisciplinar. A modo de presentación"
}

\author{
Exhumazioak eta memoria historikoa Espainian: diziplinarteko begirada \\ bat aurkezpen gisara \\ Exhumations and historical memory in Spain: an interdisciplinary view. \\ An introduction
}

\author{
Álvaro Baraibar \\ Universidad Pública de Navarra /Nafarroako Unibertsitate Publikoa \\ alvaro.baraibar@unavarra.es \\ https://orcid.org/0000-0001-5892-2604
}

La atención a las víctimas de la violencia ejercida tras el golpe militar de 1936 es, sin lugar a duda, una de las deudas que, hace ya décadas, contrajeron nuestra sociedad, nuestras instituciones y, también, la Universidad. Al miedo impuesto por la dictadura tras la victoria franquista sucedió el manto de silencio que arrojó la transición a la democracia. La memoria quedó relegada en España a un ámbito privado, familiar, apoyada por algunas escasas iniciativas impulsadas desde espacios externos a ese contexto más inmediato.

Así, reconstruir la verdad de lo sucedido era y es una de las reivindicaciones principales de miles de familias. Desenterrar la verdad es, también y en cualquier caso, una tarea ineludible de un país que tras vivir un trauma con miles de asesinatos y desapariciones forzosas -además de las múltiples formas en las que la violencia franquista se ejerció contra distintas personas y colectivos de nuestra sociedad- no supo responder a las víctimas con la empatía y cercanía que hubieran sido deseables y a las que tenían derecho. Qué duda cabe que la localización y recuperación de los cuerpos de las víctimas de la represión franquista es, más allá de una cuestión humanitaria básica, un paso fundamental en la reconstrucción de una verdad institucionalizada que repare a esas miles

* El presente dosier se ha desarrollado en el marco del proyecto de investigación «NECROPOL. Más allá del subtierro: del giro forense a la necropolítica en las exhumaciones de fosas comunes de la guerra civil» (PID2019-104418RB-I00) financiado por el Ministerio de Ciencia e Innovación. 
de familias y que sirva de base a una imprescindible deslegitimación de la violencia sobre la que erigir un relato veraz y justo de la historia contemporánea de España.

Son ya numerosas e importantes las iniciativas y proyectos que, en las últimas décadas, han avanzado en el esclarecimiento de lo sucedido tras el golpe militar. En el ámbito de las exhumaciones de las fosas del franquismo, a las actuaciones que llevaron a cabo las propias familias durante los años de la transición siguió una reactivación impulsada por las asociaciones memorialistas a comienzos del siǵlo XXI. En alǵunas Comunidades Autónomas, además, las instituciones han asumido directamente la responsabilidad de las exhumaciones atendiendo a las indicaciones que al respecto han hecho organismos internacionales sobre la base del Derecho Humanitario Internacional.

El derecho de las víctimas apela a la sociedad en su conjunto y la Universidad puede desempeñar un rol relevante desde la investigación en las distintas áreas de conocimiento que impulsa y desarrolla. Los resultados aportados por los distintos grupos de investigación orǵanizados en el ámbito de la Academia han permitido un avance fundamental en la reconstrucción de los hechos, en el análisis de las formas de represión y en la localización, recuperación e identificación de las víctimas de la violencia franquista.

El presente dosier, que hemos titulado «Exhumaciones y memoria histórica en España: una mirada interdisciplinar», nace de la voluntad de Huarte de San Juan. Geografía e Historia de contribuir a un mejor conocimiento de la violencia ejercida tras el golpe militar así como de sus consecuencias. En el dosier participa un grupo de especialistas que proyecta una mirada pluridisciplinar sobre una realidad sensible, compleja y poliédrica. Junto a autores consagrados como Pablo García Colmenares (Universidad de Valladolid) o Paco Etxeberria y Lourdes Herrasti (Universidad del País Vasco y Sociedad de Ciencias Aranzadi) encontramos un grupo de jóvenes profesionales de distintas ramas de la investigación universitaria que ha acreditado ya una gran experiencia y un no menos relevante currículum en el contexto del estudio de las exhumaciones de las fosas comunes en España. Nos referimos a Laura Muñoz Encinar (Universidad de Extremadura/Universiteit van Amsterdam, Holanda), Dorothée Delacroix (Université Sorbonne Nouvelle, Francia), Zahira Aragüuete (Université de Genève, Suiza), Lee Douǵlas (Universidade de Lisboa, Portugal) y Daniel Palacios (Universität zu Köln, Alemania). Se trata de un grupo con un importante componente de internacionalidad que nos habla del interés que suscita esta materia también fuera de nuestras fronteras, así como de la movilidad de las nuevas generaciones de profesorado universitario.

El dosier reúne un total de siete trabajos que combinan aproximaciones a las exhumaciones de fosas comunes en España desde la historia, las ciencias forenses, la arqueología, la antropología social, la cultura visual, la etnografía o la 
monumentalidad memorialista. Algunos de los trabajos tienen una mirada global, general, sobre el conjunto del territorio, y otros, en cambio, se ciñen a un espacio más concreto: la Comunidad Foral de Navarra, Castilla y León o Extremadura, por ejemplo.

Pablo García Colmenares («Exhumaciones y memoria histórica en Castilla y León. El voluntariado memorialista ante la incomparecencia institucional») analiza la realidad de una región que conoce perfectamente para proyectar una mirada crítica sobre el silencio institucional en torno a las políticas públicas de memoria en un territorio especialmente castigado por la represión franquista y en el que existe un gran número de fosas comunes (muchas ya exhumadas gracias a la actuación de familiares y asociaciones). Ante la ausencia de las instituciones la responsabilidad del trabajo por las víctimas ha sido asumida por el tejido asociativo, que ha llevado a cabo un gran esfuerzo en los distintos ámbitos de la recuperación de la memoria.

Paco Etxeberria y Lourdes Herrasti («Aportación de las ciencias forenses al principio de legalidad en la exhumación de fosas comunes en la Comunidad Foral de Navarra»), a partir de su dilatada experiencia al frente de equipos forenses y arqueológicos en las campañas llevadas a cabo en España y, concretamente, en Navarra, profundizan en su texto en dos aspectos distintos. El primero, la ausencia del poder judicial en el desarrollo de las exhumaciones y, en consecuencia, la pregunta sobre el valor pericial que las evidencias encontradas en ellas pudieran llegar a tener en la constatación «oficial» de la violencia desatada tras el golpe militar de 1936 en una hipotética comisión de la verdad. En este sentido, la conclusión a la que ambos expertos llegan es rotunda: los datos recabados serían validados y asumidos, al tener el respaldo de los procedimientos científicos empleados. El segundo se centra en el análisis de la tipología de las víctimas exhumadas en Navarra entre los años 2005 y 2020 acudiendo para ello a los datos que la Sociedad de Ciencias Aranzadi ha obtenido en las iniciativas impulsadas tanto por las asociaciones memorialistas -desde 2005- como por el propio Gobierno de Navarra -desde 2015.

El tercer trabajo es obra de Laura Muñoz Encinar («Desenterrando la represión de género: análisis de la violencia ejercida sobre las mujeres durante la Guerra Civil y la dictadura franquista en el suroeste de España»). Su artículo analiza, desde una perspectiva de género, la violencia ejercida contra las mujeres a partir de las evidencias halladas en las exhumaciones de fosas comunes de Extremadura y acudiendo, también, a otro tipo de fuentes de carácter oral y documental. Sobre una importante fundamentación arqueológica, el estudio aborda una perspectiva holística al incorporar, además, metodologías propias de la historia y de las ciencias forenses. Sus conclusiones muestran una represión específica ejercida sobre las mujeres por parte de los victimarios con una voluntad ejemplarizante. 
Los siguientes tres trabajos del dosier comparten un aspecto común: acudir al contexto de las exhumaciones de fosas comunes del franquismo como fuente para el análisis de las distintas realidades afectivas, familiares, sociales y visuales que en ellas tienen lugar. Desde una perspectiva proyectada a partir de la antropología social y la cultura visual, las tres autoras -Dorothée Delacroix, Zahira Aragüuete y Lee Douǵlas- estudian los complejos entramados que se generan y desarrollan en torno a las exhumaciones. Dorothée Delacroix («Economías afectivas y verdades parciales en el contexto de las exhumaciones en Navarra»), a partir de la información recopilada en la labor de campo llevada a cabo en torno a varias exhumaciones de fosas comunes en la Comunidad Foral de Navarra, analiza los distintos planos de lectura de una exhumación (histórico, social, familiar, político o de justicia). La interacción entre los distintos aǵentes presentes en el momento de la recuperación de los cuerpos de las víctimas genera una polifonía que aporta claves de interpretación muy relevantes para una mirada antropológica.

Por su parte, Zahira Aragüuete («Recomponer la identidad familiar de las víctimas del franquismo más allá de la fosa común») reconstruye con gran delicadeza la forma en que las investigaciones particulares que algunas personas llevan a cabo para documentar una fosa común en la que se pudiera encontrar su ser querido, dan lugar a la construcción de verdaderos archivos familiares a partir de recuerdos, documentos, fotografías... Estas colecciones de diversos objetos se llenan de memoria y permiten otras formas de enfrentarse al olvido, la impunidad y el trauma de la violencia franquista cuando la exhumación no consigue la identificación y recuperación de la víctima que había motivado la búsqueda.

Y en tercer lugar, Lee Douǵlas («Seeing like a scientist: subjunctive forensics and shared ways of seeing in the Spanish forensic archive»), desde el análisis de la cultura visual y el papel que desempeña la fotografía en los procesos exhumatorios, lanza una mirada crítica en la que quiere poner en evidencia las distintas lecturas que posibilitan las imágenes forenses que se toman en la recuperación de los restos de las víctimas. Equipos profesionales, activistas de la memoria y sociedad en general, a través de las imágenes compartidas en redes sociales y en otros soportes, participan en la visibilización de ese pasado violento y en la reconceptualización acerca de cómo deben ser leídas. Douǵlas propone que estas imágenes tienen sentidos que van mucho más allá del objetivo forense, de registro visual de los restos de una víctima, con el que fueron tomadas, y que precisan un análisis de los distintos contextos en los que son compartidas, exhibidas, contempladas e interpretadas.

El trabajo que cierra el dosier corresponde a Daniel Palacios («Prácticas monumentales postexhumación: entre el praǵmatismo y la escritura de la historia»). El artículo se fundamenta en un proyecto de investigación de más larǵo recorrido que ha analizado las prácticas monumentales desarrolladas en más de 600 fosas 
localizadas en diferentes lugares de España. Su propuesta afirma que, tras la exhumación de una fosa, el elemento que nos conecta con el pasado son los cuerpos de las víctimas y su reinhumación, cuestión que, a lo largo de las décadas, ha dado lugar a distintas prácticas monumentales. El trabajo incide en la necesidad de focalizar las investigaciones más allá de los procesos exhumatorios y dirigir la mirada hacia las formas en que los cuerpos se conservan, dignifican y recuerdan y hacia los significados que adquieren en las prácticas de reinhumación.

En definitiva, el dosier recoge siete miradas distintas que representan un aporte indiscutible al trabajo por la recuperación de la memoria de las víctimas del franquismo. Esperamos que los artículos aquí reunidos den lugar a nuevas preguntas y enfoques que permitan seguir avanzando en un mejor conocimiento de una realidad que necesita, también, un análisis profundo desde coordenadas académicas. 
